\title{
A Need-based Evaluation of the EAP Courses for the Pharmacy Students in the University of Asia Pacific (UAP), Bangladesh
}

\author{
Takad Ahmed Chowdhury ${ }^{1} \&$ Md. Zulfeqar Haider ${ }^{2}$ \\ ${ }^{1}$ Department of English, University of Asia Pacific (UAP), Dhaka, Bangladesh \\ ${ }^{2}$ Foreign Language Training Center, Ministry of Education, Dhaka, Bangladesh \\ Correspondence: Takad Ahmed Chowdhury, Department of English, University of Asia Pacific, House \# 8/A, \\ Road \# 7, Dhanmondi, Dhaka-1205, Bangladesh. E-mail: takad@uap-bd.edu
}

\author{
Received: July 29, 2012 Accepted: August 25, 2012 Online Published: November 30, 2012 \\ doi:10.5539/ass.v8n15p93 URL: http://dx.doi.org/10.5539/ass.v8n15p93
}

\begin{abstract}
The quality and effectiveness of EAP courses offered to the students aspiring to study in the private universities in Bangladesh is a matter of increasing concern for the teachers and students alike. All the 56 private universities emerged in the country within a span of not more than two decades, use English as their medium of instruction. Students of most of these universities are sorely aware of the difficulties to carry on their studies due to limited proficiency and study skills in English. Although every university in Bangladesh offers English courses which are supposed to meet the required language needs of the students of various disciplines, it is time to raise question about the efficiency of these courses and the extent they actually address the needs of the students. This study focuses on the efficacy of the EAP courses offered to the students of pharmacy discipline at the University of Asia Pacific (UAP), a private university in Bangladesh. The study examines the content and structure of the EAP courses and explores the academic as well as work-related needs of the potential pharmacy professionals to formulate strategies that may reinforce the overall effectiveness of such English language programs. The study was based on a needs-analysis survey of 40 undergraduate level students of Department of Pharmacy and four teachers who teach the EAP courses at the same university. It is found from the study that the current EAP courses have major drawbacks in meeting learners' expectations and replicating the acquired language skills for both academic and professional purposes. It is recommended that the EAP courses could be further improved by incorporating materials relevant to the core subject and by putting more emphasis on writing and speaking skills, the two productive skills that are considered most important and difficult by the students concerned.
\end{abstract}

Keywords: EAP, needs analysis, tertiary education, professional needs, pharmacy students, Bangladesh, UAP

\section{Introduction}

\subsection{Introduction to the Problem}

All the private universities in Bangladesh offer at least two semesters of English language teaching. Most offer a foundation course in the first semester covering the basic components of the language, and more advanced courses in the second semester covering topics like advanced writing, English composition, English communication skills, presentation and public speaking skills, report writing etc. Most of these courses can be classified as English for Academic Purposes (EAP).

EAP has been described as first, a move away from an emphasis on the literature and culture of English speakers towards a more practical command of the language; and, second, a move towards a view that the teaching of the language should be matched to the needs and purposes of the language learners. The English language courses taught at the tertiary level are usually EAP courses, since the objectives of these courses are not only to give students a practical command of English but also to enable them to use the language in the study of their fields of specialization. Hence, an EAP course usually begins with the learner and the situation, whereas a general English course begins with the language itself as the prime focus. In fact, most general English courses tend to teach the learners conversational and social genres of the language while EAP courses tend to teach formal and specialized academic genres.

The quality and effectiveness of the language courses offered to students aspiring to study pharmacy in English medium universities appears to be a matter of great concern because of the far reaching impact they leave on the 
academic and professional endeavors of the students concerned. The future prospects of these students are mostly contingent upon their academic success at tertiary level. Such EAP courses, therefore, must facilitate the kind of learning that ensures that the learners are placed in the best possible position to cope with the challenges of academic study as well as the typical language needs to be encountered in their professional domains.

\subsection{Importance of the Problem}

Pharmacy professionals need to interact with a variety of people in variety of contexts ranging from local community health workers to international health organizations with multicultural settings. The potential pharmacists need to be able to read and write effectively and critically in order to deal with the varied and complex problems or situations which they may encounter in their professional practice. In fact, the ability of communication has been ranked as one of the seven top qualities for the pharmacy graduates. In the report of its consultative group on Preparing the Future Pharmacist (Vancouver, 1997) the World Health Organization identified seven roles which mentioned that "The pharmacy graduate will be able to effectively use and respond to written, verbal and non-verbal communications with diverse audiences and for varied purposes. To do so, pharmacy graduates must be able to use information, media and technology." Hence, pharmacy education at tertiary levels often has a focus on developing the relevant communicative competence of the pharmacy students so that they can communicate with a wide range of audience and purpose. The EAP courses offered by the universities are expected to enhance the students' ability to think and communicate more effectively both during as well as after their course of study.

Most private universities in Bangladesh offer two to four English language courses throughout an undergraduate student's period of study. Apart from the foundation courses, which are more remedial in nature, such English courses are basically the same as the EAP courses taught worldwide, covering topics such as techniques for effective reading, summarizing, writing essays and reports, note taking etc. However one aspect that appears to be lacking in most courses is a focus on developing students' study skills which is of prime importance in an effective EAP course. Because, what the tertiary students need first and foremost are the study skills required to cope with the huge volume of reading they face on arrival in an English medium environment. The study of short texts followed by comprehension-questions can in no way equip them with the ability to interpret, digest, synthesize and evaluate the quantity of materials that they have to face. The problems students face are not only of lack of proficiency in English but also related to problems with study skills, inadequate learner training, inappropriate strategies for study, especially in the critical listening, reading and writing skills, and the culture of teacher dependence prevalent among Bangladeshi students.

Needs analysis is fundamental to any EAP approach in course designing and teaching. It leads to the specification of objectives for a course and the kinds and range of contents to be covered, and an assessment of the available resources. Needs analysis also helps identify the constraints that may be taken into account in order to maximize the effectiveness of the syllabus and methodology. The tertiary level learners in Banglaesh who get enrolled to private universities are mostly from Bangla-medium educational institutes. As they start their academic journey with the universities, they encounter huge challenge of coping with the medium of instruction e.g. English. This has a detrimental effect on the overall academic progress of those learners which may seriously impede their professional success. This problem can be addressed by designing and delivering needs-based EAP course at an early stage of academic program. This type of program is even more important for the learners of pharmacy discipline as they have very strong career prospects of working in multinational environments with specific English language needs. Therefore, this study seeks to explore the effectiveness of the EAP courses offered at UAP to identify the special language needs and priorities of the students concerned.

\subsection{Scopes and Limitations of the Study}

The study is limited to the findings based on the responses of the 40 purposively selected students of pharmacy department of UAP, Bangladesh. Although this research was carefully prepared to make a thorough needs analysis of EAP courses of Bangladeshi under-graduate students of pharmacy, there were some limitations in the study due to time and fund constraints. First of all, the research was conducted among undergraduate students of pharmacy from only one Bangladeshi private university. It would certainly be better if the study was done with a larger and more diverse group. Secondly, the students who responded to the questionnaire expressed their opinions regarding specific needs of English skills for their academic and job purposes. The study would be more complete should it be conducted on a larger scale to include responses from the pharmacy teachers and employers regarding the specific English language competencies expected from their students or prospective employees respectively. 


\subsection{Review of Literature}

\subsubsection{Scope and Purpose of EAP?}

English for Academic Purposes (EAP) is one of the two main branches of English for Specific Purposes (ESP), the other branch being English for Occupational Purposes (EOP). EAP is defined as "any English teaching that relates to a study purpose" (Dudley-Evans \& St John, 1998, p.34). It is concerned with "those communicative skills in English which are required for study purposes in formal educational systems" (Jordan, 1997, p.1). EAP courses tend to teach learners' formal, academic genres of the language rather than conventional and social genres as general English courses do (Hamp-Lyons, 2001). Gillett (1996) defined EAP as a branch of ESP considering that the teaching contents of such courses are relevant to the needs of the learners.

\subsubsection{History and Development of EAP}

EAP teaching practice has widely been carried out for almost four decades. The term "English for Academic Purposes" was first introduced in 1974 and put into general use in 1975 (Jordan, 1997). The British organization SELMOUS (Special English Language Materials for Overseas University Students) has a valuable contribution in the development of EAP. The published papers of its annual meeting were entitled English for academic purposes (Cowie and Heaton, 1977, cited in Jordan, 1997, p. 1). Later in 1989, SELMOUS was renamed BALEAP (British Association of Lecturers in English for Academic Purposes) and the professionalism in the teaching of EAP at tertiary level was then promoted. Besides, it is Strevens (1977, cited in Hamp-Lyons, 2001, p.126) who recognized EAP as an area of ESP and underlined the teaching for practical command of language and that language teaching should meet the needs of language learners.

\subsubsection{EAP Course Design and Syllabus}

Most EAP course design approaches take in to account several key factors based on needs analysis and students' difficulties in using the language. Jordan states that in designing an EAP syllabus several factors such as needs, aims, means and other variables or constraints are considered. He proposes that an EAP course primarily focuses on separate study skills that include reading comprehension, academic writing, listening comprehension and note taking, academic speech and reference skills. (p.58). However, he observes further developments and changes occurring in the 1990s that marked a shift of focus from the discrete skills to integration of skills of reading and writing with more text-based focus on writing. That kind of syllabus put more emphasis on text based tasks such as 'genre analysis, summarizing, paraphrasing and integration of source text with appropriate references'. (p.59).

Flowerdew \& Peacock (2001) look at the functions of EAP as a course "to cover those educational activities in higher education", the purpose of which is teaching and learning of the English language required by the undergraduates, postgraduates and/or staff. Their subject of study is not the English language, which is a 'carrier' subject. They need English language and communication skills for access to subject knowledge or 'content', either ..... prior to their studies or during them. (p. 25)

Looking at the EAP contexts as a potential market for the students, White (2004) underscores the need for a combination of the consumers' demands to the 'productions' offered by the educational institutions. Describing the teachers as 'the service providers', the students as 'the consumers' and the teaching-learning event as 'the process' he gives emphasis on avoiding any mismatch between the provider's and consumer's solutions to the later's problems by designing 'highly focused composite courses, combining professional/vocational needs, with EFL and new kinds of hybrid qualifications." (p. 35)

Hyland (2006) argues that the scope EAP now has gone far beyond the domains of syllabus design, needs analysis and material design. He, therefore, observes the development of an EAP that may address the diverse ways to understand and engage learners in a critical understanding of the increasingly varied contexts and practices of academic communication. Therefore, Hyland (2006) suggests a broader role of EAP courses as he says:

It (EAP) is, in short, specialized English language teaching grounded in the social, cognitive and linguistic demands of the academic target situations, providing focused instructions informed by an understanding of texts and constructions of academic contexts. (p. 2)

\subsubsection{Duration and Method of Delivery of EAP Courses}

The duration of EAP courses varies according to the setting and customized requirement of the students, and thus they can be pre-sessional, that is, full-time courses held before an academic course begins, or in-sessional, that is, courses delivered during an academic semester and students can take them while studying their major courses (Jordan, 1997). According to Jordan (1997), the length of courses is not fixed. It can be either 'short', e.g. 4 -12 weeks, or 'long', e.g. 6 -12 months, or 'longer' (Jordan, 1997, p. 2). As far as the method of delivery is concerned, 
formal teaching programs, self-access situations, distance-learning materials or CALL (computer-assisted language learning) can be the choices for EAP instruction (Jordan, 1997).

\subsubsection{EAP Settings in Bangladesh}

According to Jordan (1997), EAP exists in different settings. Teachers thus have to do a careful work before designing the course and selecting relevant teaching materials in order to match their teaching situations. Dudley-Evans and St John (1998, p.34) also pointed out that "the key determinant of what an EAP course should contain is whether or not the subject course is taught in English". For this reason, four types of EAP situation should be considered while practicing EAP teaching in tertiary level context: EAP in an English-speaking country, EAP in ESL (English as a second language) situations, EAP situations in which certain subjects are taught in English and EAP situations where subject courses are taught in the national language.

EAP setting in Bangladesh is similar to that of most ESL countries, because here English, being an official foreign language, enjoys almost like a second language status. Here English is mainly used in the education system of all levels though the native language still plays a dominant role in everyday life. The objectives of EAP courses here are to facilitate students in acquiring study skills and preparing them for the specific study at the tertiary level. But one thing to mark is the needs of such students "span the needs of non-native speakers following an English-medium course and those of native speakers in need of developing communication skills" (Dudley-Evans \& St John, 1998, p.37). The most successful communication skills course in ESL countries turned out to be the combination of the traditional ideas of EAP and the communication skills for native speakers (Dudley-Evans \& St John, 1998).

\subsubsection{Role of Common Core and Subject-specific Work in EAP}

The common core and subject specific work of EAP are undividable in the real EAP teaching practice though some scholars hold their opinions. Hutchinson and Waters (1987, cited in Dudley-Evans \& St John, 1998) and Blue (1988, cited in Dudley-Evans \& St John, 1998) argued that EGAP should be focused on in EAP teaching and ESAP can be acquired by students through individual project work. Dudley-Evans and St John made it more completed and clearer by adding that "the common-core EAP work makes more sense and is more relevant if it is supplemented by specific work" (Dudley-Evans \& St John, 1998, p.42). In addition, they suggest the three-level cooperation for subject-specific work: Cooperation, Collaboration and Team-teaching. Cooperation "involves the language teacher taking the initiative and finding out what happens in the subject department" (Dudley-Evans \& St John, 1998, p.44). On the other hand, collaboration requires the language and subject teachers to work together outside classroom. In contrast, Team-teaching refers to their in-classroom cooperation.

\subsubsection{Study Skills}

Study skills, as Longman Dictionary of Language Teaching \& Applied Linguistics defines, are: abilities, techniques, and strategies which are used when reading, writing or listening for study purposes. For example, study skills needed by university students studying from English-language textbooks include: adjusting reading speed according to the type of material being read, using dictionary, guessing word meanings from context, interpreting graphs, diagrams and symbols, note-taking and summarizing. (Richards, Platt and Platt, 2002, p.451). Jordan (1997) introduced the two concepts of study skills from another angle: productive skills and receptive skills. Productive skills include speaking in seminar/tutorial and writing in essay/report/dissertation/thesis/exam/private study. Receptive skills refer to listening (and note-taking) in lecture/seminar/tutorial as well as reading (and note-taking) in private study. He interpreted the relationship between these two types of skills as "the receptive skills are seen as necessary inputs to the productive skills, with each receptive skills having its place with each productive skill, depending on the appropriate study situation or activity" (Jordan, 1997, pp.6-7). Since students may come from different learning and cultural backgrounds, their needs of study vary widely. For this reason, the study skills are usually adopted and developed in accordance with individual situations and specific study levels (Jordan, 1997).

\subsubsection{Approaches to Teaching EAP}

Paltridge (2001) observes that, today's EAP teaching practice employs a number of approaches to highlight the language and discourse of particular academic genres rather than that in academic text. Meanwhile, the process of academic writing and the context of production and interpretation of academic text are getting much valued, too. The approaches (mainly to EAP writing) to teaching EAP as summarized by Paltridge (2001) are as follows -

1) Content-based approach, i.e., teaching the subject and language based on the teaching material at the same time. The approach of collaboration between subject specialist and EAP teacher, requires the language and subject teachers' working together, either in classroom or outside classroom. 
2) Controlled composition, an approach focusing on speaker or writer's accuracy and views the learner's native language as the hurdle in their second language acquisition. Substitution tables, written expansions and completion-types are model classroom tasks that adopt this approach.

3) The approach of teaching 'rhetorical functions', i.e., teaching descriptions, narratives, definitions, exemplifications, classifications, comparison and contrast, cause and effect, and generalizations. As a development following controlled composition, this approach focuses on the particular rhetorical patterns rather than grammatical correctness only.

4) Process approach, an approach that puts the emphasis on learners' autonomy in writing. In other words, the teacher is more like a guide than a controller. The stages of brainstorming, planning, drafting, revising, editing and proofreading the text are characteristic of relevant classroom activities.

5) The genre approach to EAP writing focuses on the teaching of particular academic genres like essays, research reports, theses and dissertations. Training students as researchers was promoted by Johns (1988, cited in Paltridge, 2001) as an effective approach to help students enrich and develop their knowledge and skills in writing texts.

\subsection{Features of the EAP Courses Offered at UAP}

The EAP courses offered at most Bangladeshi private universities have certain characteristics in common. All these are in-sessional courses spanning from one to four semesters and offered upon completion of a general English course. These courses are taught by English language teachers with no involvement of the core subject teachers and thus they have no subject-specific work throughout the course. The course contents usually include language practice activities on the four skills of English. However, there is much influence of grammar based teaching English in these courses.

The EAP courses at UAP are offered in the first two semesters of the undergraduate programs. The courses have two main parts delivered in two semesters. In both the semesters the courses offer lessons on grammatical items such as tenses, sentence types, number, adjectives, pronouns, suffixes, prefixes, transformation of sentences and so on. The composition part includes a variety of composition types - descriptive, narrative, argumentative etc. However, in the second semester, more genres of writing compositions are covered as students are required to write reports, letters, memorandum, definitions and describe charts. The courses also have some units on reading comprehension. However, there is not much scope of developing speaking skill except the oral presentations that students need to make in both semesters.

\section{Method}

\subsection{Method of Study}

In order to examine how far EAP courses at tertiary level are meeting the needs of students, this survey was conducted through questionnaires with 40 purposively selected pharmacy students of the University of Asia Pacific (UAP), Bangladesh. A structured questionnaire was developed for generating responses from the participants. The questionnaire included a total of 10 structured questions regarding the concerned English language courses. A total of 40 second year students of the university have been invited to complete the questionnaire. All these students had completed two English language courses in their first two semesters in addition to a foundation course at the beginning. The survey was conducted with a view to generating quantitative data. The data collected through structured questionnaire was compiled manually and presented in percentage. The study also generated views of the four teachers through interviews who teach the EAP program. Each of them was interviewed separately for about 10 minutes. The teachers were asked to give their views on pedagogic as well as other organizational aspects of the EAP course.

\subsection{Participant Characteristics}

The selected participants are the second year undergraduate students of UAP studying pharmacy. Most of them, (36 out of 40) have got enrolled in this university after successfully completing their Higher Secondary Certificate (HSC) Examination. The HSC course offered at Bangladeshi colleges follow the curriculum and syllabus of the National Curriculum and Textbook Board (NCTB) where the medium of instruction is predominantly Bangla. However, 4 participants have their background in English medium and they successfully completed their A levels, a higher secondary level qualification conducted under University of London. The age of the participants ranges from 18 to 21 years.

\subsection{Data Gathering Tool}

A structured questionnaire was designed and piloted among a small sample of respondents to generate data. The questionnaire was finalized after the piloting and in its final version 10 questions were included. Each question 
focuses on exploring learners' views on their current English language needs and expectations. It also includes questions on learners' future needs of specific language skills that might be important for their professional success. The questions were designed to generate data on which skills are important to learners' current and future needs and to what extent they are important. There are questions on frequency of problems faced by the learners while trying to develop each skill or sub-skills. The frequency is measured on a five point scale rubric starting with very often to never (Appendix 1).

\section{Findings}

\subsection{Findings from Students' Questionnaire}

\subsubsection{Skills Expected to Use during the Course of Study}

It is evident from the students' response that a huge percentage of students (85.5\%) expect to use writing skills very often during the course. About $50 \%$ students mentioned reading and writing as the two skills they are expected to use most frequently. Another $37.5 \%$ students find speaking skill as useful skill that they often expect to use. However, only $12.5 \%$ students have mentioned listening as a skill that they expect to use during their course of study very often. Almost $50 \%$ students find listening as a skill they expect to use only sometimes and $10 \%$ reported that they rarely use listening skills in their course of study.

\subsubsection{Frequency of Difficulty Faced with the Language Skills}

The students reported that they face difficulties very often and often with the two productive skills - speaking and writing. $32.5 \%$ and $35 \%$ students said they have difficulty with writing skills very often and often respectively while only $20 \%$ and $8 \%$ students said they encounter difficulty with their writing sometimes and rarely. Only $5 \%$ students said they have never experienced any difficulty with writing skills. It is evident that the students face difficulty with speaking skills a little bit more frequently than they do with writing skills. The findings show that $40 \%$ and $42.5 \%$ students have difficulties with speaking skills very often and often respectively while only $7.5 \%$ reported that they are having troubles with speaking skills sometimes and rarely. The frequency of facing difficulty with reading skills is comparatively low as only $10 \%$ students have reported to face it very often and $30 \%$ students reported that they face problems with this skill either rarely or never. However, another $30 \%$ students said they have troubles with reading skills often and sometimes. Listening appears to be one skill with which students are least troubled. Only 3 students said they face difficulty with listening either very often or often, only $7.5 \%$ students said they do so sometimes. $10 \%$ students said they rarely and $12.5 \%$ said they never face any difficulty with listening skills.

\subsubsection{Importance of Language Abilities for Success in Pharmacy Course}

While commenting on the importance of English language abilities for successful completion of the pharmacy course, a majority of $80 \%$ students mention the ability of writing English as a very highly important skill. The reading of English is considered a very highly important ability by $60 \%$ students and highly important by $20 \%$ students while another $20 \%$ find it an ability of moderate importance. The respondents consider the oral-aural abilities e.g. listening and speaking skills to be comparatively less important than reading and writing skills. 50\% and $27.5 \%$ students respectively have reported speaking and listening as very highly important abilities for carrying out their study successfully. $25 \%$ students think the abilities of speaking and listening as of high importance. On the other hand $32.5 \%$ and $20 \%$ students respectively find listening and speaking as moderately important abilities. It is found that $12.5 \%$ students have mentioned that listening to English has low importance for their academic success.

\subsubsection{Importance of Language Abilities for Success in Pharmacy Profession after Graduation}

It is revealed from the study that the ability of speaking in English is considered the most important ability to be successful when the students enter into the professional arena of pharmaceuticals profession. $80 \%$ students mentioned speaking as a very highly important ability while another $15 \%$ students report it to be a highly important ability they need for a successful career in pharmaceutical sector. Among other abilities, $30 \%$ and $40 \%$ students respectively have mentioned writing ability as very highly and highly important abilities. Another $25 \%$ students think of writing as moderately important for professional success. Only $15 \%$ and $12.5 \%$ students respectively have reported listening and reading abilities very highly important for their career after graduation. However, 30\% students considered each of listening and reading as highly important abilities for their professional success. It is also found that $20 \%$ and $30 \%$ students respectively consider listening and reading as abilities that have low importance for success in Pharmacy related jobs. 


\subsubsection{Types and Frequency of Problems with Speaking Skills}

The students were asked to give feedback on how often a certain type of problem happens as they try to speak in English. In response a clear majority of $40 \%$ students opined that they always have difficulty in giving oral presentation and $32.5 \%$ and $27.5 \%$ said respectively that they face the same problems often and sometimes. Another problem is being afraid of making mistakes while speaking English. 20\% students have reported to experience this problem always, $40 \%$ face this often and $32 \%$ say they sometimes have this fear of making mistakes. Only 7.5\% students opined that they have never been afraid of making mistakes while speaking in English. Regarding the problem of not knowing how to say something in English, only 10\% students said they always have this problem, $20 \%$ said often and $22.5 \%$ said they experience this problem sometimes. However $42.5 \%$ students said that they never have the problem of not knowing how to say something in English. Finding the words for what one wants to say quickly is another problem of speaking English experienced often and sometimes by $45 \%$ and $52.5 \%$ students respectively. However, only $2.5 \%$ students said to have this problem always. The difficulty of pronouncing English words is not frequently experienced by students as only $2.5 \%$ and $12.5 \%$ students reported to experience such problems always and often respectively. $67.15 \%$ students reported that they sometimes have problems pronouncing certain words while only $17.5 \%$ said they never face such problem.

\subsubsection{Types and Frequency of Problems with Listening Skills}

Responding to the types of problems faced by students while listening to English, 5\% students said that they have always troubles understanding lectures in English while 22.5\% said they often have similar problems. $30 \%$ students have reported to experience similar problems sometimes and $37.5 \%$ students said to have never experienced such troubles. Regarding note taking from lectures, $20 \%$ students said they often have problems in taking notes while $42.5 \%$ reported to have this problem sometimes. However, $35 \%$ students said they never encountered any problem in taking notes. In their responses $65 \%$ students admitted that they have troubles sometimes understanding lengthy descriptions in English as they listen to them while $30 \%$ students said they often have this problem. Only 5\% students reported to have this problem always. $12.5 \%$ and $37 \%$ of the responding students said that they have troubles always and often respectively in understanding the subject matter of a talk while $47.5 \%$ said to have never experienced such problems.

\subsubsection{Skills Required for Writing Assignments}

The students were asked to mention the skills they need to write assignments and their importance in academic context. The skills considered by students as either very important or important are, organizing assignments (92.5\%) completing writing tasks in time $(90 \%)$, using appropriate vocabulary $(90 \%)$, punctuation and spelling (77.5\%), expressing ideas appropriately $(77.5 \%)$, organizing paragraphs $(75 \%)$, adopting appropriate tone and style $(72.5 \%)$, and editing and revising $(60 \%)$. On the other hand among the skills which the students consider not important are editing and revising (35\%), adopting appropriate tone and style (20\%), organizing paragraphs (17.5\%), punctuation and spelling (12.5\%) etc.

Regarding the frequency of facing problems in the above mentioned skills areas, $10 \%$ says they have often have problems with spelling and punctuation. However, $45 \%$ say they sometimes have problems with spelling and punctuation and $30 \%$ say that they never have problems in this area. $45 \%$ students they have difficulty with using appropriate vocabulary sometimes while another $45 \%$ say they have never had any problem regarding using appropriate vocabulary. Only $10 \%$ said they have often problems with finding the right words. Organizing ideas for assignments and organizing paragraphs appear to be two areas in which the students have problems less frequently. $62.5 \%$ and $57.5 \%$ students respectively said that they never had any problems with organizing ideas for assignments and organizing paragraphs. However 30\% and 35\% students said that they have sometimes problems in these two areas of writing skills. Editing and revising the writing is another area which students found as less problematic. $62.5 \%$ students said they have had never any problem in this area while only $27.5 \%$ say they have experienced problems with editing and revising their writings sometimes.

\subsubsection{Types of Materials Expected to Read during the Course}

Students responded to two questions concerning the reading tasks required of them during the course. While commenting on the types of reading materials they expect to read during the course, a big majority of $90 \%$ students ticked 'yes' to indicate that they read 'photocopied notes' as part of their reading tasks. Only 5\% students ticked 'no' indicating that they don't expect to read 'photocopied notes' during the course. Regarding 'materials from internet' $85 \%$ students said 'yes' and 15\% said 'no'. Among other types of reading materials $85 \%$ said 'yes' to 'reference/textbook' comparing to $20 \%$ students saying 'no'. Again, while $75 \%$ students said 'yes' for 'journal articles' $20 \%$ said 'no'. $72.5 \%$ students mentioned reading materials like newspaper articles 
and workbook/instructions, with $30 \%$ students saying 'no' in these categories. The type of reading materials that most of the students said 'no' about is 'work of fiction'. 90\% students said 'no' comparing only $10 \%$ saying 'yes' for this type of reading materials.

Regarding frequency of difficulty faced with each type of reading materials, it is found that $40 \%$ students often, and another $40 \%$ students sometimes have difficulty reading journal articles. Again, $25 \%$ and $27.5 \%$ students face difficulty often and sometimes respectively with the reading of reference or textbooks. Although only $10 \%$ students said to have difficulty reading newspaper articles often, a huge $70 \%$ students said they find them difficult only sometimes. Students appear to be less frequently troubled by the other types of reading materials such as photocopied notes, workbook or instructions and materials from the internet. However, $55 \%$ students said they have never faced any difficulty with reading photocopied notes.

\subsubsection{Frequency of Difficulty with Reading Skills}

Students were asked to comment on how often they have difficulty with various sub-skills that involves reading of a text. In response a highest $57.5 \%$ students said they have difficulty guessing unknown words in a text either very often or often. $20 \%$ students find it difficult very often to read a text slowly and carefully in order to understand the details while another $32.5 \%$ students said they often have this problem. Again, $47.5 \%$ students said they often have problems looking through a text quickly in order to locate specific information and $30 \%$ said they have the same problem only sometimes. A good number of students talked about having problem with their reading speed; $10 \%$ students said they have very often and another $45 \%$ said they often have problems with their reading speed. Another problem area identified by the students is the ability to read something critically. According to the responses $12.5 \%$ students have this problem very often and another suffer from this problem often. It is revealed that understanding the main point of a text is a problem that happens very often to $20 \%$ students, often to 8 and sometimes to $45 \%$ students. Reading a text quickly to get a general idea of the content appears to be another problem that students struggle with very often, $30 \%$ often and $50 \%$ sometimes. Among other areas of problem which are experienced by students less frequently are- understanding text organization ( $7.5 \%$ very often, $25 \%$ often, $25 \%$ sometimes), understanding specialist vocabulary in a text $(17.5 \%$ very often, $30 \%$ often, $45 \%$ sometimes) and understanding writer's attitude and purpose ( 2 very often, 10 often, 25 sometimes).

\subsection{Findings from Teachers' Interviews}

The second part of the study was conducted through interviews of the English language teachers teaching EAP courses to the pharmacy students at UAP regarding effectiveness of their courses. Most were of the opinion that the existing courses follow the conventionally established methodology of imparting four language skills to the students with no incorporation of materials relevant to their core subject. Thus, according to most of them, there is a lack in understanding of the particular academic and professional needs of the pharmacy students enrolled at tertiary level, and ways to address those needs within the course. The students cannot relate their English courses with their major area of study and they consider their English courses an obstacle that just needs to be removed, taking into no account of their long-lasting impact in achieving academic and professional goals. The English teachers also noted that the EAP courses are offered only in the initial semesters of four-year pharmacy undergraduate course, so the students get three years to forget the skills that they may have learnt. It was also observed that courses are also crammed with unnecessary items such as memo writing or cover-letter writing in their very first year, which can be called a waste of time since students would really benefit from them more at their pre-departure stage, especially in a country likes Bangladesh where the notion of students' working and studying at the same time is almost an alien concept. One of the main complaints of teachers of English language has always been that even after twelve years of English language learning, most of the students who enter the universities have such a low level of proficiency that the English courses have become in reality, nothing more than remedial. As a consequence the level of proficiency of most of the students, coupled with the amount of time and effort that put into "re-learning" makes it all the more harder to teach within such a limited timeframe.

\section{Discussions}

The findings reveal some significant features of the EAP courses offered to the pharmacy students of UAP. It is evident that students expect to use writing and reading skills the most during their study. Speaking is also mentioned as a useful skill for the duration of the course but listening has been identified as the least required skill. On the other hand, the two productive skills, writing and speaking, have been identified as the most difficult with which students struggle most frequently. Though reading skill has been mentioned by the students as one of the two most required skills to develop, it does not appear to pose much difficulty to most of the 
students. However, both writing and speaking have been found to be among the most expected as well as most difficult skills and there is a need to give maximum importance on these two skills during the course. The current course outlines show that only 8 out of 42 hours of lessons are allocated on writing related activities and there are only 4 hours spent on speaking skills. Moreover, the course syllabus is heavily based on teaching of grammar in isolation which does not directly contribute to the overall development of any of the expected skills as identified in this study. The findings call for redesigning the EAP courses by giving special importance on developing writing, reading and speaking skills to meet the expectations of maximum students and to address the most frequently faced problem areas.

As writing skill has been identified as the most important as well as difficult skill for the students, various sub-skills of writing have also been looked at in the study. It appears from the study that most students have problem with finding the appropriate vocabulary while writing assignments. A good majority of students have also mentioned some mechanical aspects of writing such as spelling and punctuation etc. as their problem areas. It is, however, evident that there are specific focus on spelling rules, punctuation and capitalization in the current EAP syllabus. Another area of concern as revealed from the study is the problem of organizing the piece of writing and adapting appropriate tone and style. The courses offered to the students provide practice opportunities of different types of writing compositions such as descriptive, narrative, argumentative and biography but has no specific focus on many of the aforementioned sub-skills that the students are found to be more perplexed with. Therefore, the units of writing skills can be redesigned incorporating some important sub-skills such as organizing assignments, using appropriate vocabulary, expressing ideas appropriately, organizing paragraphs, adopting appropriate tone and style and editing and revising.

Another area of concern revealed from this study is the gap between the skilled required of the students during and after the course of study. For example, a high majority of $80 \%$ and $60 \%$ students respectively mentioned the ability of writing and reading English as very important skills for success in their course of study. However, when it comes to the question of success in the professional arena after graduation, speaking is considered the most important ability by $80 \%$ respondents. Thus, it is evident that the degree of importance the pharmacy students give on a particular language skill for their academic success does not match with the skills they need for success in their professional life. This gap between the academic and professional needs of the students could be bridged by putting more importance on speaking skills within the EAP course so that the potential pharmacy professionals may develop this most desired language skill for their professional success. This need for emphasizing on speaking skill becomes more pertinent when specific problem areas of using English are identified in this study. It is found that $40 \%$ students have always difficulty in giving oral presentations and $60 \%$ face the same problem either often or sometimes. More than $60 \%$ admit that they are afraid of making mistakes, either always or often, while speaking English. These findings again substantiate the need for putting much more emphasis on speaking skill in the EAP program.

Reading skill is considered one of the most important skills for academic success of the students and they are required to a read only a limited amount and types of reading materials. It is found that students are exposed to read photocopied notes, materials from the internet reference or textbooks and journal articles during their course of study. Though it is found from the survey that the maximum number of students face difficulty with reading journal articles and reference or textbook books, they are not much exposed to these types of reading materials. They are most likely to read photocopied notes which do not pose much difficulty among the students. It is, therefore, suggested that students could be more exposed to reading materials in the form of journal articles and text/reference books which require higher level of reading skills.

Listening skill seems to have the least impact on the academic as well as professional success of the pharmacy students. In fact, 5\% students reported to have troubles understanding lectures in English always and 37.5\% students said to have never experienced such troubles. The EAP course followed at UAP contains some units on recognizing sounds such as vowel sounds and homophones. One reason for this is all the lectures are given by the Bangladeshi non native speakers of English. Considering the least amount of problems faced by students in listening to English lectures, these phonemic units could be replaced by more speaking and writing items.

\section{Recommendations}

From the above findings it can be suggested that the EAP courses for the pharmacy students of UAP should certainly follow the specific needs and overall academic interest of the students. To make the English courses more relevant to the core subject, the courses can be redesigned and some customized course materials can be developed in collaboration with the faculties from pharmacy discipline. While redesigning the course, the following important points could be considered: 
1) There should be more emphasis on developing content related writing skills required for both academic and professional success.

2) The lessons on writing should give importance on developing sub-skills such as using vocabulary, organizing the paragraphs, adapting appropriate tone and style and editing and revising.

3) There should be focus on developing different genres of writings such as reports, assignments, arguments, analytical reports etc.

4) Students should be exposed to more challenging reading texts such as journal articles and text/reference books including scholarly articles/essays related to pharmacy.

5) Speaking skills is particularly important for pharmacy students' success in their professional fields and this skill needs to be specially developed during the course of study.

6) Most students have problems with giving oral presentations. There must be special emphasis on developing oral presentation skills.

7) There is no need to spend much time on listening skills practice, specially practicing sounds and phonemic features of English.

8) Self-access facilities should be provided for the students to ensure regular practice of the different skills taught in English language courses.

\section{Conclusion}

This study attempts to identify the problems and needs of English language skills for the undergraduate pharmacy students of UAP. The major findings show that there is much scope for improving the course by redesigning the contents, curriculum and program framework. Particularly, as it appears from the study, there is a need for bridging the existing gap between the academic and professional language needs of the pharmacy graduates. The course contents can be made more relevant as well as interesting in order to make the EAP course more effective as well as motivating for the students concerned. It is also revealed from the study that the EAP course should address the ultimate professional and academic interests of the learners so that they find the course worth studying and thus develop the required level of communicative competence as potential pharmacists. The EAP course may include language practice components facilitating abilities such as higher order thinking skills, synthesis and evaluation of information from various sources and concise written communication for a range of purposes. These objectives could be achieved, besides curriculum changes, through a variety of pedagogical reforms including self-study facilities, individual/group presentations or seminars, group projects and content related reading and writing tasks.

\section{References}

Dudley-Evans, A., \& St. John, M. J. (1998). Developments in ESP: A Multi-disciplinary Approach. Cambridge: Cambridge University Press.

Flowerdew, J., \& Peacock, M. (2001). Research Perspectives on English for Academic Purposes. Cambridge: Cambridge University Press. http://dx.doi.org/10.1017/CBO9781139524766

Gillett, A. (2000). What is EAP? IATEFL ESP SIG Newsletter, 6, 17-23. Retrieved from http://www.uefap.com/articles/eap.htm

Hamp-Lyons, L. (2001). English for Academic Purposes. In R. Cater, \& D. Nunan (Eds.), The Cambridge guide to teaching English to speakers of other languages. Cambridge: Cambridge University Press. http://dx.doi.org/10.1017/CBO9780511667206.019

Hyland, K. (2006). English for Academic Purposes: An advanced resource book. New York, Routledge.

Jordan, R. R. (1997). English for academic purposes: A guide and resource book for teachers. Cambridge: Cambridge University Press. http://dx.doi.org/10.1017/CBO9780511733062

Paltridge, B. (2001). Linguistic research and EAP pedagogy. In J. Flowerdew, \& M. Peacock (Eds.), Research perspectives on English for academic purposes. Cambridge: Cambridge University Press. http://dx.doi.org/10.1017/CBO9781139524766.007

Richards, J. C., Platt, J., \& Platt, H. (2002). Longman Dictionary of Language Teaching \& Applied Linguistics. Beijing: Longman \& Foreign Language Teaching and Research Press.

White, R. (2004). The Ivory tower in the marketplace. In L. E. Sheldon (Ed.), Directions For The Future: Issues In English For Academic Purposes (pp. 31-39). Bern: Peter Lang. 
World Health Organization. (1997). The Role of the Pharmacist in the Health Care System - Preparing the Future Pharmacist: Curricular Development, Report of the Third WHO Consultative Group on the Role of the Pharmacist. Vancouver, Canada. Retrieved from http://apps.who.int/medicinedocs/pdf/s2214e/s2214e.pdf

\section{Appendix1. Needs Analysis Questionnaire for EAP Students}

1) In your course of study, how often are you expected to use the following skills? (please select):

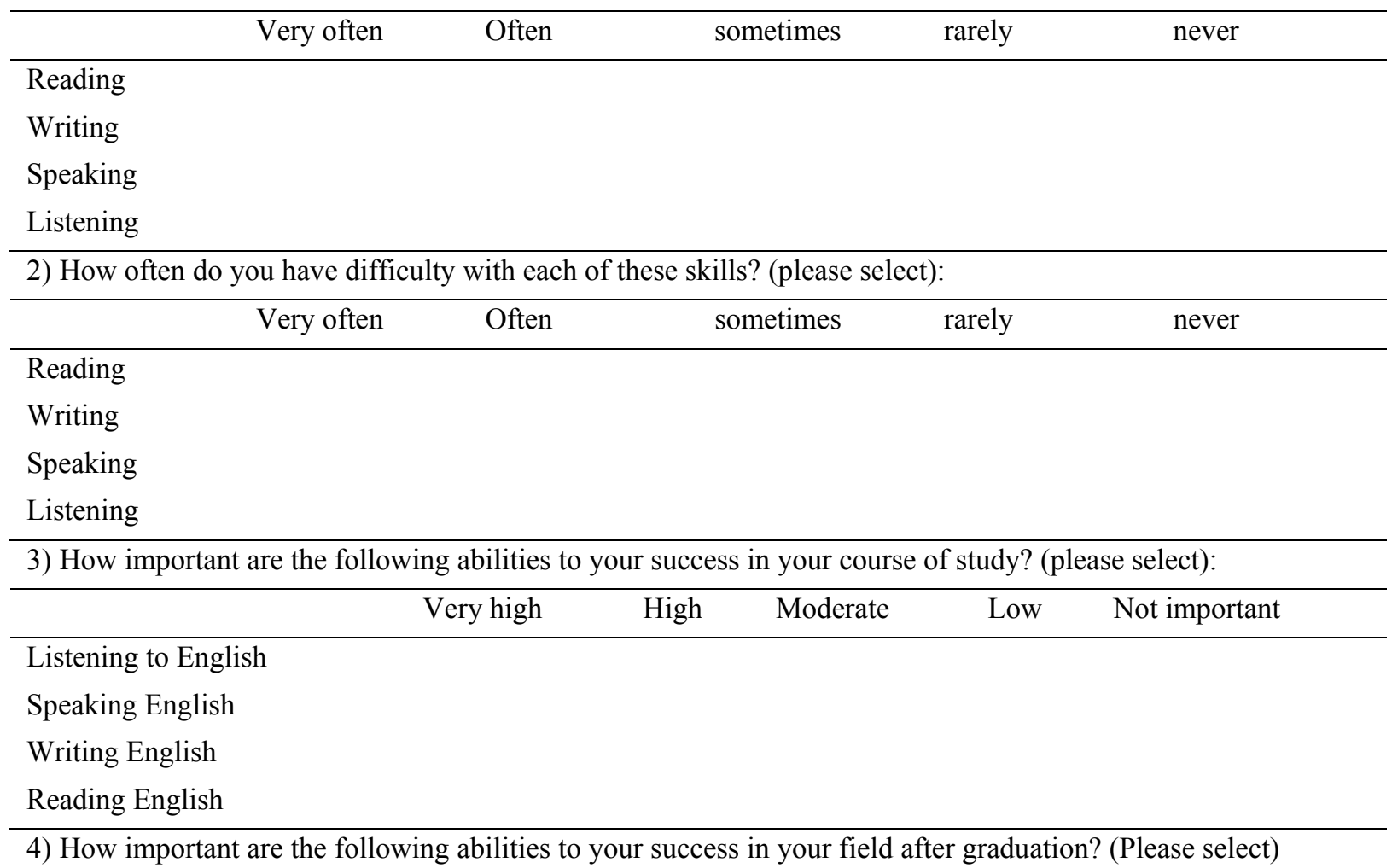

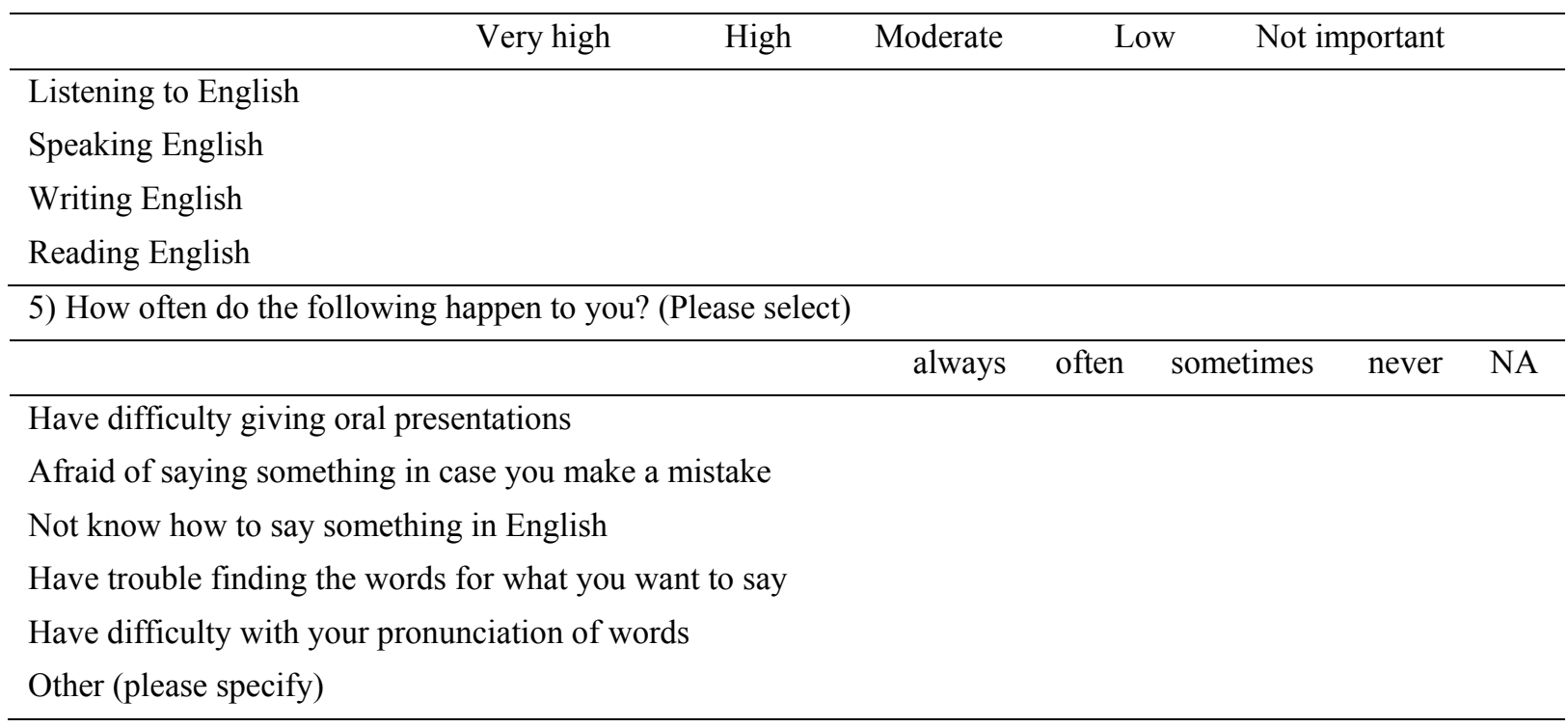


6) How often do the following happen to you? (Please select)

\begin{tabular}{|c|c|c|c|c|c|c|c|c|}
\hline \multirow{2}{*}{\multicolumn{9}{|c|}{ Have trouble understanding lectures }} \\
\hline & & & & & & & & \\
\hline \multicolumn{9}{|c|}{ Have trouble taking notes } \\
\hline \multicolumn{9}{|c|}{ Have trouble understanding lengthy descriptions in English } \\
\hline \multicolumn{9}{|c|}{ Have trouble understanding the subject matter of a talk } \\
\hline \multicolumn{9}{|c|}{ You also have difficulty with (please specify) } \\
\hline \multicolumn{9}{|c|}{$\begin{array}{l}\text { 7) With regard to writing assignments, please indicate for each of the following by encircling a number. } \\
\text { a. How important the skills is ( } 1=\text { very important, } 2=\text { important, } 3=\text { not important, } 4=\mathrm{N} / \mathrm{A}) \\
\text { b. How often you have problems with the skill ( } 1=\text { often, } 2=\text { sometimes, } 3=\text { never, } 4=\mathrm{N} / \mathrm{A})\end{array}$} \\
\hline \multicolumn{4}{|c|}{ How important } & Problems & & \multicolumn{3}{|c|}{ Frequency of problem } \\
\hline 1 & 2 & 3 & 4 & Using correct punctuation and spelling & 1 & 2 & 3 & 4 \\
\hline 1 & 2 & 3 & 4 & Using appropriate vocabulary & 1 & 2 & 3 & 4 \\
\hline 1 & 2 & 3 & 4 & Organizing paragraphs & 1 & 2 & 3 & 4 \\
\hline 1 & 2 & 3 & 4 & Organizing the overall assignment & 1 & 2 & 3 & 4 \\
\hline 1 & 2 & 3 & 4 & Expressing ideas appropriately & 1 & 2 & 3 & 4 \\
\hline 1 & 2 & 3 & 4 & Adopting appropriate tone and style & 1 & 2 & 3 & 4 \\
\hline 1 & 2 & 3 & 4 & Editing and revising your writing & 1 & 2 & 3 & 4 \\
\hline 1 & 2 & 3 & 4 & Completing writing tasks in time & 1 & 2 & 3 & 4 \\
\hline 1 & 2 & 3 & 4 & Others (please specify) & 1 & 2 & 3 & 4 \\
\hline
\end{tabular}

8) The following questions concern the reading tasks required of you during the course.

a) Which of the following types of material you are expected to read? (Please select)

b) How often you have difficulty doing so? (Please select)

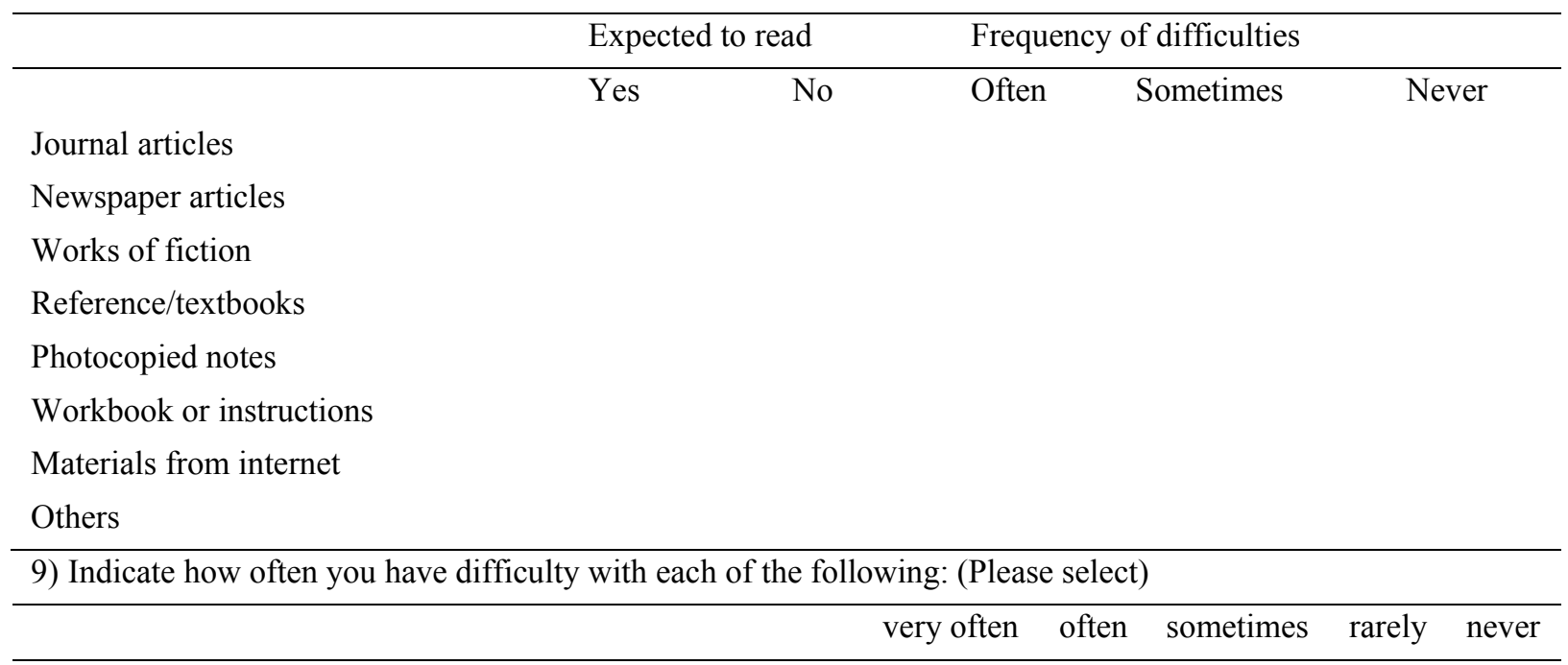

Understanding the main points of text

Reading the text quickly to get a general idea of the content

Reading a text slowly and carefully in order to understand the details

Looking through a text quickly in order to locate specific information

Guessing unknown words in a text 
Understanding text organization

Understanding specialist vocabulary in a text

Reading speed

Reading in order to respond critically

Understanding writer's attitude and purpose

General comprehension

Other (please specify)

\section{Appendix 2. EAP Course Outline for the Pharmacy Students at UAP}

1) Course No: HSS 101 (Course Title: English Language I)

\section{Grammar:}

a) Tenses-Past, Present, Future

b) Uses of Prepositions

c) Affirmative, Negative \& Interrogative Sentences

d) Uses of Definite and Indefinite Articles in Singular and Plural Sentences

e) Pronouns and Possessives

f) Prefixes and Suffixes

g) Spelling Rules

h) Adjectives: Comparative and Superlative degrees

i) Punctuation and Capital Letters

j) Transformation of Parts of Speech and their uses in sentences: Noun, Adjective, Verb, Adverb

k) Vowel Sounds

1) Homophones and Homonyms

\section{Books Recommended:}

a) Raymond Murphy: Intermediate English Grammar

b) John and Liz Soars: Headway Pre-Intermediate $\left(3^{\text {rd }}\right.$ Edition)

c) W. Stannard Allen: Living English Structure

d) Donne Byrne: Intermediate Comprehension Passages

\section{Composition:}

a) Writing Biography (using third person in different tense form)

b) Writing Road Direction (using Preposition)

c) Writing Descriptions

d) Writing Narratives (writing a story based on pictures)

e) Writing Comparative Paragraphs (using degree of comparison)

f) Comprehension/ Summarizing

g) Translation from Bangla to English

h) Oral Presentation

\section{Assessment:}

a) Class Attendance: 5\%

b) Presentation \& Assignment: 15\% (8+7)

c) Class test: $10 \%$

d) Mid Term: $20 \%$

e) Term Final: $50 \%$

f) Total: $100 \%$

Lesson Plan (Total Number of Class Hours: 42)

\begin{tabular}{|c|c|c|c|}
\hline $\begin{array}{l}\text { Class } \\
\text { Hours }\end{array}$ & Topic & $\begin{array}{l}\text { Class } \\
\text { Hours }\end{array}$ & Topic \\
\hline 1 & $\begin{array}{l}\text { Introduction: An overview of the } \\
\text { course }\end{array}$ & 2 & $\begin{array}{l}\text { Uses of Definite/ Indefinite Articles in Singular/ } \\
\text { Plurals }\end{array}$ \\
\hline 3 & Tense - Past, Present and Future & 2 & Describing Objects \\
\hline 2 & $\begin{array}{l}\text { Affirmative, Negative and } \\
\text { Interrogative Sentences }\end{array}$ & & $\underline{3^{\text {rd }} \text { Class Test }}$ \\
\hline 2 & Writing Biography & 3 & $\begin{array}{l}\text { Adjectives: Comparative and Superlative } \\
\text { Sentences and Paragraphs }\end{array}$ \\
\hline & $\underline{1^{\text {st }} \text { Class Test }}$ & 3 & $\begin{array}{l}\text { Writing Narratives (writing stories based on } \\
\text { pictures) }\end{array}$ \\
\hline 2 & Preposition & 2 & Homophones and Homonyms \\
\hline
\end{tabular}




\begin{tabular}{llll}
2 & Writing Road Directions & 2 & Vowel Sounds \\
2 & $\begin{array}{l}\text { Rules of Punctuation and Capital } \\
\text { Letters }\end{array}$ & 2 & Comprehension \\
2 & $\begin{array}{l}\text { Prefixes and Suffixes } \\
2^{\text {nd }} \text { Class Test }\end{array}$ & 2 & $\begin{array}{l}\text { Translation from Bangla to English } \\
\text { Class Test } 4\end{array}$ \\
2 & Practice and Revision Class & 2 & Oral Presentation \\
& Mid-term Examination & 2 & Revision Class \\
2 & Transformation of Parts of Speech & Final Examination \\
\hline 2 Course No: HSS 103 (Course Title: English Language II) &
\end{tabular}

\section{Grammar:}
b) Error Analysis
c) Voice: Active, Passive
d) Confusing Words
e) Synonyms, Antonyms
f) Reported Speech
g) Conditional Sentences enough, since, for
i) Relative Pronouns
j) Phrases
k) Modal Verbs

a) Subject-Verb Agreement

h) Conjunctions - Joining words \& Phrases, Uses of too,

\section{Composition:}

a) Report Writing - Survey Report, Newspaper Report, Reporting an Event
b) Chart Analysis
c) Letter Writing -formal, informal
d) Memorandum/Memo Writing
e) Definition Writing
f) Writing Paragraphs
g) Reading Comprehension
h) Oral Presentation

\section{Books Recommended:}

a) Raymond Murphy: Intermediate English Grammar

b) Imhoof \& Hudson: From Paragraph to Essay

c) Donne Byrne: Intermediate Comprehension Passages

d) A.Ashley: Oxford Handbook of Commercial Correspondence

\section{Assessment:}

a) Class Attendance: 5\%

b) Presentation \& Survey Report: 15\% $(8+7)$

c) Class test: $10 \%$

d) Mid Term: $20 \%$

e) Term Final: $50 \%$

f) Total: $100 \%$

\begin{tabular}{|c|c|c|c|}
\hline \multicolumn{4}{|c|}{ Lesson Plan (Total Number of Class Hours: 42) } \\
\hline $\begin{array}{l}\text { Class } \\
\text { Hours }\end{array}$ & Topic & $\begin{array}{l}\text { Class } \\
\text { Hours }\end{array}$ & Topic \\
\hline 1 & $\begin{array}{l}\text { Introduction: An overview of } \\
\text { the course }\end{array}$ & 1 & Discussion on Mid-term Answer-scripts \\
\hline 2 & Subject-Verb Agreement & 2 & $\begin{array}{l}\text { Report Writing - Survey Report, Newspaper Report, } \\
\text { Reporting an Event }\end{array}$ \\
\hline 3 & $\begin{array}{l}\text { Error Analysis } \\
\text { Corrections }\end{array}$ & 2 & Chart Analysis \\
\hline 2 & Voice: Active \& Passive & 2 & Letter Writing -formal/ informal \\
\hline \multirow[t]{2}{*}{2} & Reported Speech & & $\underline{3^{\text {rd }} \text { Class Test }}$ \\
\hline & $\underline{1^{\text {st }} \text { Class Test }}$ & 2 & Memorandum/Memo Writing \\
\hline 2 & Conditional Sentences & 2 & Definition Writing \\
\hline 2 & $\begin{array}{l}\text { Conjunctions: Joining Words } \\
\text { \& Relative Pronouns }\end{array}$ & 4 & $\begin{array}{l}\text { Paragraph Writing: Kinds of Paragraphs, Topic Sentences, } \\
\text { Cohesive Devices, Transition, Supporting Ideas }\end{array}$ \\
\hline
\end{tabular}




\begin{tabular}{|c|c|c|c|}
\hline 2 & $\begin{array}{l}\text { Modal Auxiliary Verbs } \\
\text { Idioms and Proverbs }\end{array}$ & 3 & $\begin{array}{l}\text { Reading Comprehension } \\
\underline{4}^{\text {th }} \text { Class Test }\end{array}$ \\
\hline 1 & Synonyms \& Antonyms & 2 & Oral Presentation \\
\hline & Confusing Words & 2 & Revision Class \\
\hline & $2^{\text {nd }}$ Class Test & & Final Examination \\
\hline
\end{tabular}

Mid-term Examinations 